\title{
Relationship between Bishop Score and Success of Induction of Labour in Federal Teaching Hospital, Abakaliki, Ebonyi State
}

\author{
Arinze Chidiebele Ikeotuonye ${ }^{1}$, Chidebe Christian Anikwe ${ }^{{ }^{*}}$, Johnson Akuma Obuna ${ }^{1}$, \\ Bartholomew Chukwunonye Okorochukwu2 ${ }^{2}$, Brown Nnamdi Ejikeme1, \\ Chinedu Chukwuemeka Ifemelumma ${ }^{1}$, Ifeoma Cecilia Ekwunife ${ }^{1}$, \\ Francis Chigozie Okoroafor ${ }^{1}$
}

\footnotetext{
${ }^{1}$ Department of Obstetrics and Gynaecology, Federal Teaching Hospital Abakaliki Ebonyi State, Abakaliki, Nigeria

${ }^{2}$ Department of Obstetrics and Gynaecology, Federal Medical Centre, Owerri, Nigeria

Email: *drchideanikwechristian@gmail.com, Arinze790@gmail.com, obuna2003@y ahoo.com,

barthychuks@gmail.com, ifyekwunife730@gmail.com,ifemelummachinedu@gmail.com,

franokoroafor@gmail.com, henrybee2001@yahoo.com
}

How to cite this paper: Ikeotuonye, A.C., Anikwe, C.C., Obuna, J.A., Okorochukwu, B.C., Ejikeme, B.N., Ifemelumma, C.C., Ekwunife, I.C. and Okoroafor, F.C. (2018) Relationship between Bishop Score and Success of Induction of Labour in Federal Teaching Hospital, Abakaliki, Ebonyi State. Open Journal of Obstetrics and Gynecology, 8, 980-992.

https://doi.org/10.4236/ojog.2018.811099

Received: August 2, 2018

Accepted: September 4, 2018

Published: September 7, 2018

Copyright (c) 2018 by authors and Scientific Research Publishing Inc. This work is licensed under the Creative Commons Attribution International License (CC BY 4.0).

http://creativecommons.org/licenses/by/4.0/ c. (7) Open Access

\begin{abstract}
Background: The ripeness of the cervix is of critical importance to the probability of successful labour induction. Aim: To determine the relationship between successful induction of labour and Bishop score. Materials and Methods: A retrospective study of all obstetric patients who had induction of labour between January $1^{\text {st }} 2012$ and December 31st 2015 was done in Federal Teaching Hospital Abakaliki. The information obtained from patients' case notes was analyzed using descriptive and inferential statistics at an alpha level of 0.05 for all statistical tests. Results: During the study period, there were 9548 deliveries; $2.76 \%$ (264) was by induction of labour with success rate of $75.4 \%$. The mean age of the women was $28.4 \pm 5.8$ years; majority where nulliparous $(45.45 \%)$. The most common indication for induction of labour was postdatism (43.94\%). Success of induction of labour was most likely at Bishop score of 8 to $10(\mathrm{OR}=0.79,95 \% \mathrm{CI} 0.72-0.84)$. Induction delivery interval was shortest with use of Foley catheter and misoprostol. Conclusion: Our study has shown that success of induction of labour was most likely at Bishop Score of $8-10$. We advocate the use of Foley catheter and misoprostol for cervical ripening especially when there is need to expedite delivery.
\end{abstract}

\section{Keywords}

Bishop Score, Induction of Labour, Induction Delivery Interval, Latent Period Interval, Misoprostol 


\section{Introduction}

The ultimate goal of antenatal and intrapartum care is to deliver a healthy baby to a healthy and satisfied mother. It is anticipated that spontaneous successful vaginal delivery will occur; keeping in mind the rising rate of caesarean section and its attendant sequelae, but many times labour may have to be induced for various maternal and fetal reasons [1]. The favorability or ripeness of the cervix is of critical importance to the probability of successful induction of labour (IOL) and should be assessed prior to induction of labour [2]. Presently, the systematically assessed cervical status known as Bishop score (BS) is mostly used in deciding whether, how and when to induce labour [3]. It helps to predict the success of vaginal delivery [4]. In Bishop score, the dilatation, effacement, consistency, position of the cervix and station of the fetal head are assessed by vaginal examination [3] [5]. A score of 4 indicates that the cervix is not ripe for induction of labour and requires the use of pre-labour induction agents while 6 and above is thought to be favorable with a higher chance of success [3] [4]. The score was put forward by Bishop in 1964 and modified by Burnett in 1966 [3]. In the original Bishop score, each item was scored in a range from zero to two or three points and subsequently combined into a single score with a maximum of 13 [3]. Among women who scored nine and above, induction of labour did not fail [3]. According to modified Bishop (Calder score), effacement has been replaced by cervical length in centimeters [5]. Addition of Bishop score modifiers is another modification in which a point was to be added for presence of pre-eclampsia and for every previous vaginal delivery; while a point was to be subtracted for patients with postdate pregnancy, nulliparity and pre-labour rupture of membranes [5]. The classical digital examinations are subjective and have intra and inter observer variability [6]. Bishop score though used to evaluate the success of induction of labour, is not a good method of predicting birth outcomes since its sensitivity is $24 \%$ - $64 \%$ [4] [7]. In recent years, cervical sonographic evaluation has been found more sensitive than Bishop score in the prediction of successful labour [4] [6] [8]. However Watson et al. found out that the measurement of cervical length by ultrasound was not superior to digital examination of the cervix [4]. Several other reports comparing the use of ultrasound and Bishop's score did not show clear cut differences in outcome. Transvaginal ultrasound was not shown to improve on the prediction of cervical inducibility obtained by the Bishop score [6]. A prospective study on 80 patients by Dimassi et al. showed mean Bishop score of 6.48 [8]. The study revealed that the use of an ultrasound scoring system instead of Bishop score for pre-induction cervical assessment was a useful tool in predicting labour outcome [8].

Studies show that nearly $13 \%-20 \%$ term patients require induction of labour [1] [4]. In United States of America, the prevalence rate of induction of labour was reported to occur in $23.2 \%$ of deliveries [9] unlike in Africa where it is underutilized with an unmet need of $66 \%-80.2 \%$ [9]. In Nigeria, it accounts for $6.3 \%$ of deliveries [9]. Induction of labour accounted for $2.9 \%$ of deliveries over 
a 5-year period in Ebonyi State Teaching Hospital, Abakaliki [10] and induction rate of $11.5 \%$ [11] and $12.7 \%$ [9] have been reported in other studies in Nigeria. A global survey of patterns and outcome of induction of labour in Africa and Asia showed that oxytocin titration is the most common method used in $45.9 \%$ of cases and success rates were comparable in over $80 \%$ of the cases [12]. In a retrospective study by Ivars J et al., the mean Bishop score at induction was $5.75 \pm$ 1.4 [13] and the factors associated with success of induction of labour were fetal station, cervical effacement and parity [13]. They noted that cervical position and consistency are not necessary for predicting the success of induction of labour by oxytocin and amniotomy [13]. Gokturk et al. in a study in Turkey among 223 parturient recorded a successful vaginal delivery rate of $31.9 \%$ with $36.6 \%$ of their study population having cesarean delivery [4]. They also found no statistically significant difference among women in terms of age, gestational age, height and weight [4] and successful induction.

Navve et al. in Israel, showed that women with a Bishop score less than 6, had length of induction of labour longer than women who had Bishop score of 6 and above [7] thus emphasizing the importance of favorable Bishop score before commencing induction of labour. The study however noted that Bishop score is not a good predictor for success of induction of labour [7] unlike the work of Ahmadi SH et al. that Bishop score positive predictive value of $90.4 \%$ and the negative predictive value was 30.9\% [14]. The study showed that Bishop score of $\geq 6$, parity and gestational age were effective in prediction of successful delivery following induction and that cervical dilation was an appropriate index for the prediction [14]. This finding on Bishop score was supported by the work of Admani et al. in Nairobi [15]. Since a good number of women undergo induction of labour in the process of delivery, knowledge of factors that improve its outcome will not only ensure its success but also reduce the rate of caesarean section that may follow a failed induction of labour and its attendant morbidity and mortality. This study was embarked upon to help fulfill the above and also to fill knowledge gap since no such study has been done in our center. The objectives of the study are:

1) To determine whether there is any relationship between Bishop score and labour induction;

2) To determine the Bishop score at which successful induction of labour is most likely.

\section{Materials and Methods}

\subsection{Study Background}

This retrospective study was carried out at the Obstetrics and Gynaecology department of the Federal Teaching Hospital Abakaliki, Ebonyi state, Nigeria. Federal Teaching Hospital Abakaliki is the only tertiary hospital in the state located at the centre of the state and receives referrals from all parts of the state and neighbouring states of Abia, Benue, Cross -River and Enugu. The department 
of Obstetrics and Gynaecology is managed by 27 consultants and 80 resident doctors with the help of trained midwives. There are 10 teams with two teams running their clinics on each working day. The antenatal clinic holds daily from Mondays through Fridays, so also the booking clinic. The clinics are run by Consultant Obstetricians with their teams of resident doctors. When the patients are in labour, they are received at the labour ward by the midwives, manned by a senior registrar and other junior resident doctors, under the supervision of a labour ward consultant. Patients for induction of labour are usually admitted in the antenatal ward by the Team for assessment. Baseline investigations are done which include: Packed cell volume, urinalysis, HIV screening after obtaining consent, grouping and cross matching of two units of blood, biophysical profile and other tests depending on the clinical condition of the patients. The neonatologists and anaesthetists are informed. Bishop score (BS) of six (6) and above is accepted as a favourable BS for induction of labour according to the departmental protocol. The Bishop score of the parturient is determined by either the team consultant or the team senior registrar. Those with unfavourable BS of less than 6 would undergo cervical ripening while those with favourable BS would undergo induction. The decision on the methods used for cervical ripening and induction of labour is made by the team consultant. Successful induction is defined as parturient that achieved vaginal delivery. Ethical approval was obtained from the ethical committee of the Federal Teaching Hospital Abakiliki, Ebonyi state. The ethical approval number is FETHA/REC/VOL1/2017/493.

\subsection{Data Collection}

After ethical approval was obtained from the ethical committee of the hospital, case records numbers of patients that had induction of labour after 28 weeks gestation between January $1^{\text {st }} 2012$ and December 31st 2015 were obtained from the record book of the labour ward and postnatal ward making sure to avoid double entries. The hospital numbers were used to retrieve the case records from the Record department and they are reviewed. Some of the information obtained included the biodata, the indication for IOL, pre-induction BS and the materno-neonatal outcome. The total number of deliveries under the period of review was obtained. The study population included booked and unbooked patients who underwent induction of labour for various indications in this facility over the period of time of the study after 28 weeks gestation.

\subsection{Data Analysis}

Data obtained from the patient's case notes were entered into a predesigned proforma and analyzed using IBM SPSS Statistics version 20 (IBM Corp., Armonk, NY, USA) Results were presented in frequency tables, pie and bar charts. Associations between categorical data were analyzed using Chi square and f-test (ANOVA), with a p-value of $<0.05$ considered statistically significant. 


\section{Results}

The total number of deliveries during the study period was 9548 with 264 deliveries after IOL. This gave IOL rate of $2.76 \%$. The rate of success of induction of labour in the study was $75.4 \%$. In this study, parity, booking status, pre-induction Bishop Score, latency period and latent period interval were factors recorded to influence significantly the success of induction of labour. As shown in Table 1, the age range of the participants was $15-44$ years with a mean age of $28.41 \pm 5.8$ years. Less than half of the women $(45.45 \%, 120)$ were nulliparous. Majority $(86.36 \%)$ of patients were booked. A cross tabulation was done using the maternal age, parity and pre-induction Bishop score as dependent variables and mode of delivery as independent variable. The result showed a significant association between maternal parity $\left(X^{2}(\mathrm{~N}=264),=15.60, \mathrm{p}=0.013\right)$ and pre-induction bishop score $\left(X^{2}(\mathrm{~N}=264)=127.1, \mathrm{p}=0.001\right)$ with mode of delivery. Cohort of women with BS of 8 to 10 have increased odd of achieving vaginal delivery (OR $0.7995 \%$ CI 0.72 - 0.84) compared with those with BS less than 8. The odds of achieving vaginal delivery in the cohort of women with BS of more than 10 is $62 \%$ more than in the group with BS less than 10 with the true population effect that is between $69 \%$ and $55 \%$. This result was statistically significant $(p=0.001)$.

Table 2 shows that postdatism was the commonest reason for induction of labour accounting for 116 (43.94\%) of cases while chronic hypertension was least accounting for $2(0.76 \%)$ of cases.

More than half $(150,56.82 \%)$ of the patients had cervical ripening and induction of labour with $50 \mathrm{ug}$ of misoprostol; $16(6.06 \%)$ had cervical ripening with both Foley catheter and $25 \mathrm{ug}$ of misoprostol. The route of administration of misoprostol was vaginal in all cases. Induction delivery interval range was 5 hours to 12 hours. The mean induction delivery interval for misoprostol was 8 hours 28 minutes \pm 44 minutes. The induction delivery interval for Foley catheter and subsequent oxytocin titration in escalating doses was 3 to 12 hours, with a mean of 8 hours 15 minutes \pm 43 minutes, whereas induction delivery interval for patients who received both agents (Foley catheter and misoprostol) was 4 hours 20 minutes to 8 hours with a mean of $5.94 \pm 1.44$ hours $(\mathrm{p}=0.0005)$. The mean latency period for misoprostol was 5 hours 50 minutes \pm 1 hour $29 \mathrm{mi}$ nutes, that for Foley catheter was 1 hour 3 minutes \pm 12 minutes and for both was 1 hour 45 minutes \pm 1 hour 32 minutes $(\mathrm{p}=0.001)$. The mean latent period interval was 6 hours 12 minutes \pm 1 hour 21 minutes for misoprostol, 2 hours 19 minutes \pm 2 hours 18 minutes for Foley catheter and 3 hours 39 minutes \pm 1 hour 54 minutes for both ( $\mathrm{p}=0.001)$ (Table 3 ).

From Table 4, less than seven percent (15) of the neonate were severely asphyxiated. Majority had successful vaginal delivery.

Fetal distress was the commonest reason for failed induction 31 (46.97\%) as shown above. Majority of the women that were delivered by caesarean section were grand multiparas and the diagnosis of fetal distress and CPD were more common compared to other parities. $\mathrm{CPD}$ and cervical dystocia accounted for 
Table 1. Sociodemographic and obstetrics characteristics.

\begin{tabular}{|c|c|c|}
\hline Parameters & Frequency & Percentage \\
\hline \multicolumn{3}{|l|}{ Age (years) } \\
\hline $15-19$ & 4 & $1.51 \%$ \\
\hline $20-24$ & 40 & $15.15 \%$ \\
\hline $25-29$ & 124 & $46.97 \%$ \\
\hline $30-34$ & 74 & $28.03 \%$ \\
\hline $35-39$ & 20 & $7.58 \%$ \\
\hline $40-44$ & 2 & $0.76 \%$ \\
\hline Total & 264 & $100 \%$ \\
\hline \multicolumn{3}{|l|}{ Parity } \\
\hline 0 & 120 & $45.45 \%$ \\
\hline 1 & 34 & $12.89 \%$ \\
\hline 2 & 39 & $14.77 \%$ \\
\hline 3 & 30 & $11.36 \%$ \\
\hline 4 & 17 & $6.44 \%$ \\
\hline 5 & 14 & $5.30 \%$ \\
\hline 6 & 10 & $3.79 \%$ \\
\hline Total & 264 & $100 \%$ \\
\hline \multicolumn{3}{|l|}{ Booking status } \\
\hline Booked & 228 & $86.36 \%$ \\
\hline Unbooked & 36 & $13.64 \%$ \\
\hline Total & 264 & $100 \%$ \\
\hline \multicolumn{3}{|l|}{ BS before IOL } \\
\hline $6-7$ & 108 & $40.91 \%$ \\
\hline $8-10$ & 156 & $59.09 \%$ \\
\hline Total & 264 & $100 \%$ \\
\hline
\end{tabular}

Table 2. Indications for Induction of labour.

\begin{tabular}{ccc}
\hline Indications for Induction & Frequency & Percentage \\
\hline Postdatism & 116 & $43.9 \%$ \\
IUFD & 52 & $19.70 \%$ \\
Preeclampsia & 26 & $9.85 \%$ \\
PIH & 24 & $9.09 \%$ \\
Term PROM & 14 & $5.30 \%$ \\
Eclampsia & 10 & $3.79 \%$ \\
GDM & 10 & $3.79 \%$ \\
Congenital anomalies & 4 & $1.52 \%$ \\
Chronic hypertension & 2 & $0.76 \%$ \\
Others & 6 & $2.27 \%$ \\
Total & 264 & $100 \%$ \\
\hline
\end{tabular}

IUFD—intrauterine fetal death; PIH—Pregnancy induced hypertension; PROM-Premature rupture of membrane; GDM-Gestational diabetes mellitus. 
Table 3. Method of cervical ripening/induction.

\begin{tabular}{ccc}
\hline Method & Frequency & Percentage \\
\hline Misoprostol & 150 & $56.82 \%$ \\
Foley catheter & 98 & $37.12 \%$ \\
Foley \& Misoprostol & 16 & $6.06 \%$ \\
Total & 264 & $100 \%$ \\
\hline
\end{tabular}

Table 4. Maternal and neonatal outcome.

\begin{tabular}{|c|c|c|}
\hline Variable & Frequency & Percentage \\
\hline \multicolumn{3}{|l|}{ Blood loss } \\
\hline$<250 \mathrm{ml}$ & 98 & $37.12 \%$ \\
\hline $250-500 \mathrm{ml}$ & 166 & $62.88 \%$ \\
\hline$>500 \mathrm{ml}$ & - & - \\
\hline \multicolumn{3}{|l|}{ Episiotomy } \\
\hline Yes & 56 & $21.21 \%$ \\
\hline No & 208 & $78.79 \%$ \\
\hline \multicolumn{3}{|l|}{ Mode of delivery } \\
\hline VD & 198 & $75.00 \%$ \\
\hline $\mathrm{C} / \mathrm{S}$ & 66 & $25.00 \%$ \\
\hline \multicolumn{3}{|c|}{ Apgar score $\left(1^{\text {st }}\right.$ minute $)$} \\
\hline$\leq 6$ & 67 & $25.38 \%$ \\
\hline $7-8$ & 72 & $27.27 \%$ \\
\hline$>8$ & 125 & $47.35 \%$ \\
\hline \multicolumn{3}{|c|}{ Neonatal weight (kg) } \\
\hline$<2.5$ & 18 & $6.82 \%$ \\
\hline $2.5-3.5$ & 184 & $69.70 \%$ \\
\hline$>3.5$ & 62 & $23.48 \%$ \\
\hline Total & 264 & $100 \%$ \\
\hline
\end{tabular}

VD-vaginal delivery; C/S—caesarean delivery.

$34.85 \%$ and $18.18 \%$ of cases of caesarean delivery respectively (Figure 1).

Figure 2 shows that as parity increases the success of vaginal delivery also increases. Parturient undergoing their $4^{\text {th }}$ delivery had the highest success rate of 93.30\% with the lowest in primigravida. Primigravidae had the highest rate of caesarean delivery followed by women undergoing their $7^{\text {th }}$ delivery.

\section{Discussion}

A total of 9548 deliveries were recorded during the study period; 264 of them had induction of labour giving an induction of labour rate of $2.76 \%$. This was 

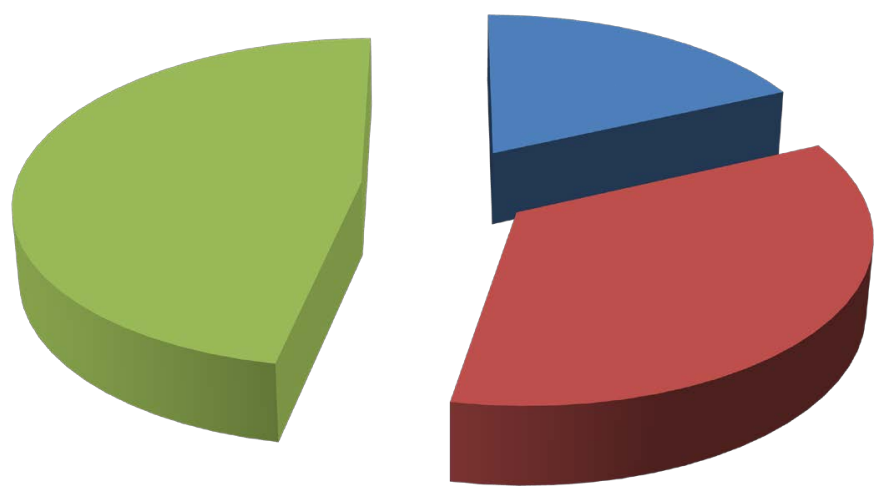

- Cervical dystocia

- CPD

Fetal distress

Figure 1. Reason for failed Induction. CPD-cephalopelvic disproportion.

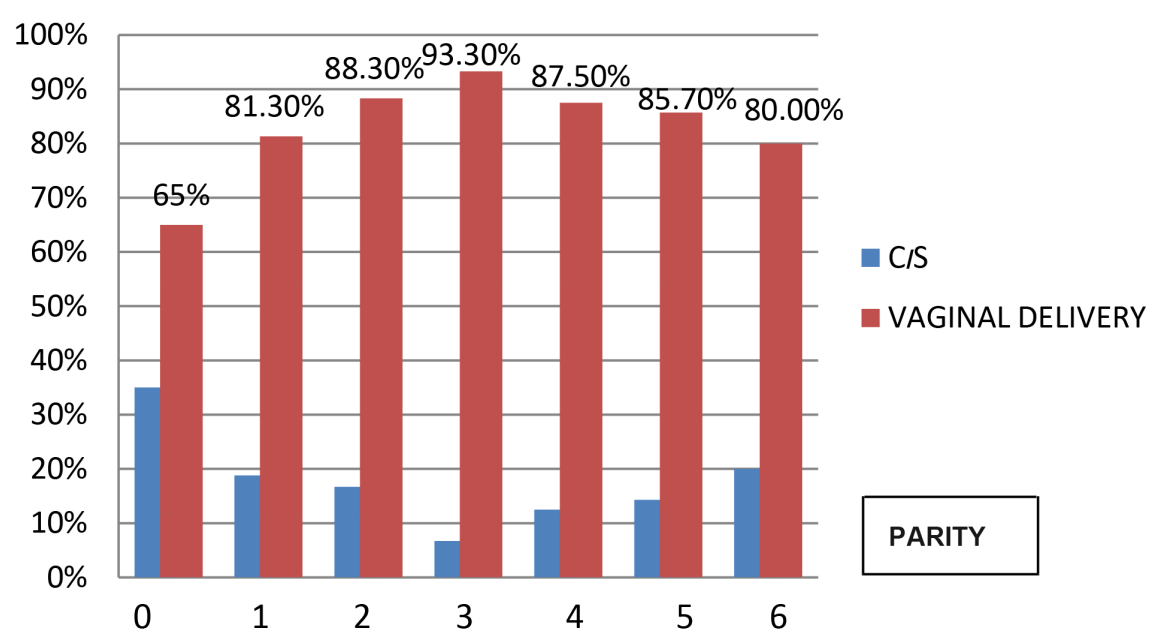

Figure 2. Relationship of success of Induction of labour and parity.

similar to values of 2.9\% recorded in Ebonyi state university teaching hospital, Abakaliki (EBSUTH) [10] and was also comparable to studies in Jos and Sokoto where $4.5 \%$ and $3 \%$ were reported respectively [16]. However higher rates of labour induction were reported in Cross River, Nigeria (11.5\%) [11] and United States of America (23.2\%) [9]. The similarity with a study by Obuna et al. [10] might be due to the fact that EBSUTH where the study was conducted is now a component of FETHA with similar patient characteristics while the difference could be accounted for by difference in patient characteristics and the increased unmet needs for induction of labour in Africa [9].

The success rate of induction of labour in the study was $75.4 \%$ which is comparable to other studies in Nigeria which recorded a success rate of $75.9 \%$ in Cross River, $83.1 \%$ in Abakaliki and $82.2 \%$ in Jos [16]. However, higher success rate of more than $90 \%$ was reported in Sokoto, Nigeria by Ekele et al. [17]. The success rate in our centre is however higher than the rate reported by Admani $e t$ al. [15] and Gokturk et al. [4] in Nairobi and Turkey respectively. The similarities or differences recorded may be due to similarities or differences in patient characteristics in the different study population as well as difference in practice and environment. Majority of the patients were booked $86.36 \%$ while $13.64 \%$ 
were not. This may account for the high success rate seen in this study. Lawani et al. [11] reported that $86.2 \%$ of their participants were booked which was comparable to that of this study and not surprisingly, similar success rate were also recorded in both studies. The mean age of participants in this study was $28.41 \pm 5.8$ years, which was similar to the mean age of $27.51 \pm 8.37$ years reported by Lawani et al. [11] but lower than the value gotten by Bello et al. [9]. It is however higher than the mean age of $25.9 \pm 4.2$ years and 22.2 years reported by Woubishet et al. [18] and Mehta et al. [19] respectively. Difference in study population is the plausible reason for this finding. Postdate accounted for the highest indication for induction of labour (43.94\%), while intra uterine fetal death accounted for $19.70 \%$. A similar modal indication was noted in a similar study in Nigeria [10] [16] however, hypertensive disorders in pregnancy were the second highest in these studies unlike in our review.

Multiparity and Bishop score were a major predictor for successful induction of labour in our study which was also recorded in Admani et al's study [15]. In this study however, success increased from para 0 to para 3 and then decreased from para 4 to para 6 . This may not be unconnected with the fact that increase in adverse outcome of pregnancy and labour is often associated with grand multiparity, hence accounting for the increased cesarean section among this group that was seen in our review. Other factor that might account for the increased failure rate among this group might be attributed to increased lordosis that occurs with increase in parity that might explain the number of cephalopelvic disproportion seen.

Failed induction of labour in this study was mainly due to fetal distress accounting for $46.97 \%$, followed by cephalopelvic disproportion (34.85\%) and then cervical dystocia (18.18\%). This was similarly noted in Lawani et al. study [11]. However, the third cause of failed induction in their study was cord prolapse and this was not recorded in our study. Gokturk et al. [4] also recorded fetal distress as the commonest cause of failed induction $(60.6 \%)$ and poor progress accounting for $36.6 \%$ while Mehta et al. [19] reported failed progress (48.14\%) as the commonest followed by fetal distress (31.48\%). Causes of failed induction are usually grouped into maternal and fetal as above and as such the similarities are not surprising.

Misoprostol was the commonest method of cervical ripening and induction of labour in this study accounting for $56.82 \%$ and was similar to findings by Lawani et al. [11] in Cross River, Nigeria even though misoprostol was used more often than was seen in our study. At pre-induction Bishop score of 8 and 10, the likelihood of vaginal delivery is highest and this was statistically significant with Chi square value of 127.1 and p-value of 0.001. Navve et al. [7] recorded that at Bishop score of less than 6 , the length of induction of labour was longer than in women that had Bishop score of 6 and above which is in support of our findings. The induction delivery interval (IDI) was noted to be shorter in patients that had cervical ripening with both Foley catheter and misoprostol and with or without subsequent oxytocin titration in escalating doses depending on clinical findings. 
The mean IDI was 5 hours 29 minutes \pm 1 hour 32 minutes, while the mean IDI for Foley catheter was 6 hours 21 minutes \pm 2 hours 27 minutes and for misoprostol was 8 hours 28 minutes \pm 1 hour 56 minutes. The overall mean IDI noted in this study was 7.20 hours \pm 2.43 hours. In a similar study Woubishet et al. [18] reported a mean induction delivery of 6:10 \pm 3:09 hours. Ahmadi et al. [14] reported a mean induction delivery interval of $9.8 \pm 1.4$ hours. However a higher mean IDI of $12 \pm 3.6$ hours was reported by Lawani et al. [11]. This study suggests that synchronous use of Foley catheter and misoprostol has a reduced induction delivery interval and very effective in cervical ripening; it should therefore be considered in clinical situation where there is need to hasten delivery in the presence of an unfavorable cervix.

Induction of labour is not a trivial procedure in obstetric practice and should be embarked upon when requisite conditions are fulfilled with adequate client selection. This is important in achieving a good outcome. In a retrospective study on the intrapartum correlates of successful induction of labour using oxytocin and misoprostol in Ebonyi state it was shown that the outcome of IOL is positively influenced by parity, booking status, pre-induction Bishop score, latency period and latent period interval [10]. The above findings were supported by our study. Ivars et al. [13] in their study also reported that fetal station and cervical effacement were factors associated with success of induction of labour which was not seen in our review. This might be expected as these parameters are subjective in their assessment. Gokturk et al. [4] in Turkey found that multiparity status, cervical length, posterior cervical angle and Bishop score are possible predictors of successful labor induction with fetal station not able to predict. Credence to this finding was seen in our review that shows a significant association between Bishop score and successful induction. Our study shows an increase odd of a parturient delivering vaginally with increase in Bishop score (OR $0.6295 \%$ CI 0.55 - 0.69) as might be expected as Bishop score represent the parturient nearness to spontaneous onset of labour.

\section{Conclusion}

There is a relationship between Bishop score and induction of labour. Success of induction of labour was most likely at pre-induction Bishop score of 8 - 10 . Synchronous use of Foley catheter and misoprostol was a more effective method of cervical ripening using the induction delivery interval obtained from the study which was statistically significant.

\section{Recommendation}

We recommend that induction of labour should be commenced at a Bishop score of 8 - 10 and Bishop score should be assessed prior to commencement of induction of labour as it is an important factor in its success or failure. A randomized control trial is needed to properly assess the relationship between $\mathrm{Bi}$ shop score and success of induction of labour. 


\section{Limitations of the Study}

This study is a retrospective, hospital based study that does not represent the general population. Difficulty in sourcing data from the patient's folder due to incomplete recording of data was observed in this study. There are also different protocols for cervical ripening employed by the different units in the department, even though the process of oxytocin titration is same. There may also have been intra observer/inter observer differences in vaginal assessment for the $\mathrm{Bi}$ shop score.

\section{Declarations}

Ethics approval and consent to participate: Ethical approval for the study was obtained from the Research and Ethics committee of the hospital.

\section{Consent for Publication}

Not applicable.

\section{Availability of Data and Material}

All data generated or analysed during this study are included in this published article.

\section{Competing Interests}

The authors declare that they have no competing interests.

\section{Funding}

Funding is borne by the authors.

\section{Authors' Contributions}

CCA \& ACI: participated in the study design, data collection/analysis and interpretation of finding and drafting of manuscript. JAO \& CCI: participated in the interpretation of findings and data analysis. BCO: participated in study design, interpretation of findings and drafting of manuscript. FCO: conceptualized the study and participated in the interpretation of finding, ICE \& BNE: participated in the interpretation of findings and writing of manuscript. All participated in the review of final manuscript. All the authors approved the manuscript.

\section{References}

[1] Ali, J., Hebbar, S. and Rai, L. (2015) Alternative to Bishop Score to Predict Successful Induction of Labour. International Journal of Current Research, 7, 11632-11640.

[2] Wing, D.A. (2013) Principles of Induction of Labour. http://www.uptodate.com/contents/principles-of-induction-of-labour

[3] Kolkman, D.G., Verhoeven, C.J., Brinkhorst, S.J., van der Post, J.A, Pajkrt, E., Mol, B.J., et al. (2013) The Bishop Score as a Predictor of Labour Induction Success: A Systematic Review. American Journal of Perinatology, 30, 625-630. 
https://doi.org/10.1055/s-0032-1331024

[4] Gokturk, U., Cavkaytar, S. and Danisman, N. (2015) Can Measurement of Cervical Length, Fetal Head Positon and Posterior Cervical Angle Be an Alternative Method to Bishop Score in the Prediction of Successful Labour Induction. The Journal of Maternal-Fetal \& Neonatal Medicine, 28, 1360-1365. https://doi.org/10.3109/14767058.2014.954538

[5] Newman, R.B., Goldenberg, R.L. and Iams, J.D. (2008) Comparison of Cervical Score and Bishop Score for Prediction of Success of Induction of Labour. Obstetrics \& Gynecology, 112, 508-515. https://doi.org/10.1097/AOG.0b013e3181842087

[6] Bansiwal, R., Rao, R., Misra, N. and Kapur, V. (2013) Bishop Score and Transvaginal Ultrasound for Preinduction Cervical Assessment: A Randomized Clinical Trial. International Journal of Reproduction, Contraception, Obstetrics and Gynecology, 2, 611-615. https://doi.org/10.5455/2320-1770.ijrcog20131224

[7] Navve D., Orenstein N., Ribak, R., Daykan, Y., Shechter-Maor, G. and Biron-Shental, T. (2016) Is the Bishop-Score Significant in Predicting the Success of Labour Induction in Multiparous Women. American Journal of Obstetrics \& Gynecology, 214, S337. https://doi.org/10.1016/j.ajog.2015.10.679

[8] Dimassi, K., Erray, S., Ben Amor, A., Triki, A. and Gara, F. (2016) Predicting the Success of Labour Induction: Bishop Score versus Ultrasound Score. Obstetrics \& Gynecology, 48, 221.

[9] Bello, F.A. and Akinyotu, O.O. (2016) Prediction of Successful Induction of Labour at a Tertiary Obstetric Service in Southwest Nigeria. Tropical Journal of Obstetrics and Gynaecology, 33, 143-148. https://doi.org/10.4103/0189-5117.192213

[10] Obuna, J.A., Umeora, O.U.J., Ejikeme, B.N. and Agwu U.M. (2010) Pre-Induction and Intrapartum Correlates of Successful Induction of Labour Using Oxytocin and Misoprostol. Ebonyi Medical Journal, 9, ebomed.v9i2.71683. https://doi.org/10.4314/ebomed.v9i2.71683

[11] Lawani, O.L., Azubuike, K.O., Iyoke, C.A., Okafo, C.N, and Ajah, L.O. (2014) Obstetric outcome and significance of labour induction in a health resource poor setting. Obstetrics and Gynecology International, 2014, Article ID: 419621.

[12] Vogel, J.P., Souza, J.P. and Gulmezoglu, A.M. (2013) Patterns and Outcomes of Labour in Africa and Asia: A Secondary Analysis of the WHO Global Survey on Maternal and Neonatal Health. PLOS One, 8, e65612.

https://doi.org/10.1371/journal.pone.0065612

[13] Ivars, J., Garabedian, C., Devos, P., Therby, D., Carlier, S., Subtil, D., et al. (2016) Simplified Bishop Score Including Parity Predicts Successful Induction of Labour. European Journal of Obstetrics \& Gynecology and Reproductive Biology, 203, 309-314. https://doi.org/10.1016/j.ejogrb.2016.06.007

[14] Ahmadi, S.H., Rahmani, E., Motamed, N., Ghorbanpoor, M. and Maneshi, H. (2016) Bishop Score Predictive Value in Success of Induced Labor Process among Full Term Pregnant Women Referred to Persia Gulf Martyrs Hospital in Bushehr in 2013. Iranian South Medical Journal, 19, 620-628.

https://doi.org/10.18869/acadpub.ismj.19.4.620

[15] Admani, R., Wanyoike, G.J. and Odawa, F.X.O. (2014) Predictors of Successful Induction of Labour in Post Term Pregnancies at Kenyatta National Hospital Nairobi. Journal of Obstetrics \& Gynaecology of Eastern and Central Africa, 26, 45-50.

[16] Oyebode, T.A., Toma, B.O., Shambe, I.H., et al. (2015) Induction of Labour at Jos University Teaching Hospital Jos, Nigeria: A Four Year Review. International Journal of Research in Medical Sciences, 3, 1944-1948. 
https://doi.org/10.18203/2320-6012.ijrms20150305

[17] Ekele, B.A., Nnadi, D.C., Gana, M.A., Shehu, C.E., Ahmed, Y. and Nwobodo, E.I. (2007) Misoprostole Use for Cervical Ripening and Induction of Labour in Nigeria Teaching Hospital. Nigerian Journal of Clinical Practice, 10, 234-237.

[18] Woubishet, G., Fitsum, T. and Mirkuzie, W. (2016) Outcome of Induction and Associated Factors among Term and Post Term Mothers Managed at Jima Specialized Hospital: A Two Year Retrospective Analysis. Ethiopian Journal of Health Sciences, 26, 123-132.

[19] Mehta, K., Kuma, D., Fathepuriya, D.S. and Verma, L. (2017) Incidence of Cesarean Delivery after Induction of Labour with Dinoprostone Gel at Term in Nulliparous Women with Unfavourable Bishop Score. International Journal of Reproduction, Contraception, Obstetrics and Gynecology, 6, 1253-1257.

https://doi.org/10.18203/2320-1770.ijrcog20170956 